Tectonophysics 2009 , vol. 471 , pp. 171-185

doi:10.1016/j.tecto.2009.02.009

\title{
Crustal and upper mantle velocity structure in Yunnan, Southwest China
}

\author{
Xi Zhang ${ }^{\mathrm{a}}$, and Yanghua Wang ${ }^{\mathrm{b}}$ \\ a State Key Laboratory of Lithosphere Evolution, Institute of Geology and Geophysics, Chinese Academy \\ of Sciences, Beijing 100029, China \\ ${ }^{\mathrm{b}}$ Centre for Reservoir Geophysics, Department of Earth Science and Engineering, Imperial College \\ London, SW7 2BP, UK
}

\begin{abstract}
Four wide-angle seismic profiles acquired in analogue form in the 1980's from Yunnan, Southwest China, are re-digitized and re-interpreted for a detailed P-wave velocity structure of the crust and lithospheric mantle. The results reveal that the crust can be divided roughly into upper, middle and lower crusts with bottom depths of $17-25,26-33$, and $33-56 \mathrm{~km}$, respectively. The Moho depth varies from $56 \mathrm{~km}$ in the north of Yunnan to about $33 \mathrm{~km}$ in the southern part, and from 38-40 km in the west of Yunnan to $42 \mathrm{~km}$ in the eastern zone. The velocity anisotropy in the lower crust is of $4.4 \%$, in contrast with the very low values estimated for the upper-middle crust, which are close to $1.6 \%$. This suggests that the surface deformation in the Yunnan area is decoupled from the lower crustal flow. The seismic velocity discrepancy along different azimuths in the lower crust and upper mantle beneath the profiling cross points leads to a flow regime in the north-south direction that agrees with contemporary tectonic deformation, and also provides evidence for the rotation of the lower crust-upper mantle medium around the east Himalayan foreland. High-velocity anomalies in the lower crust might be explained as intrusions of mantle material or remaining patches of ancient oceanic crust.
\end{abstract}

Keywords: wide-angle seismic reflections, P-wave velocity model, geodynamic implications, Yunnan, Southwest China.

\section{Introduction}

The study area, Yunnan Province in southwest China, exhibits a complicated tectonic framework owing to long-term squeezing and subduction exerted by the Indian plate against the Tibet platform in the north and the Yangtze platform in the east since the early Proterozoic. It is one of the most seismically active regions in continental China with frequent occurrence of volcanoes, hot springs, and moderate-to-strong earthquakes of body-wave with magnitudes ranging from 5.0 to 7.4. To understand the deep structure of the area, two research projects were carried out in 1982 and 1986-1987, called "Dianshen 82" and "Dianshen 86", respectively. These two projects included four wide-angle seismic transects in different directions. In this paper, we use these seismic data to reconstruct the P-wave velocity structure of the crust and lithospheric mantle in the region.

Previous interpretations based on a homogeneous-layering assumption produced some onedimensional (1-D) crustal velocity models (Yan et al., 1985; Hu et al., 1986; Kan et al., 
1986; Lin et al., 1993). The average P-wave velocity of the crust is about $6.2 \mathrm{~km} / \mathrm{s}$ and its thickness varies between approximately $58 \mathrm{~km}$ under the northern part of Yunnan and 32 $\mathrm{km}$ beneath its southern border. A feature that should be emphasized is the existence of a 10 $\mathrm{km}$-thick low velocity layer at $26-36 \mathrm{~km}$ depth. However, only simple information such as the average velocity and thickness of the crust were obtained with the interpretation methods available in the 1980's. Therefore, it is of great significance to re-interpret these wide-angle seismic profiles with modern technology, to obtain a fine seismic velocity structure of the region. The modern interpretation methods used in this paper include finite-difference traveltime inversion (Hole, 1992; Ammon and Vidale, 1993) and the Raylnvr technique (Zelt and Smith, 1992), which are capable of imaging the heterogeneous media. The methodologies are flexible in the parameterization and inversion processes, and have high stability, fast computation and the ability to generate reliable solutions. We use these methods to reconstruct a two-dimensional (2-D) P-wave velocity model as an overall view of the investigated domain.

Geologically, the Yunnan region is divided into four main tectonic units (Fig. 1): TibetYunnan fold system (A), Indochina fold system (B), Songpan-Garze fold system (C) and Yangtze platform (D) (Wang and Gang, 2004; Zhang et al., 2005a,b; Zhang and Klemperer, 2005). The Tibet-Yunnan fold system (A), including the Tengchong and Baoshan blocks, is considered to be the northern segment of the Burma-Thailand-Malaysia micro-continent. Since the Cenozoic, the Indian continent has been continuously squeezing the Eurasian continent, which has developed an active magma process in Tengchong with exposed acidic intrusive rocks everywhere (Wang et al., 2002). The focal mechanism of the shocks in Tengchong and adjacent areas shows that the zone is dominated by compress-shear action exerted by intermediate-depth earthquakes in Myanmar just at the eastern margin of the Indian plate (Jiang, 1985).

The Indochina fold system (B) is a strip-like tectonic terrain whose stratum and paleontological signature are comparable with that of Yangtze platform. This fold system is located at a position where different blocks collide, subduct, suture and overlap each other. The strong tectonic action from the Late Paleozoic, especially during Yanshanian and Himalayan orogeny, causes convergence interactions, suture and overlapping among the different blocks (Huang and Cheng, 1987). In contrast, the Yangtze platform (D) was always a stable tectonic unit from the Late Paleozoic, which now exhibits a thick sedimentary cover. Some fold movement to different degree began to occur only in the course of the Yanshanian and Himalayan orogenic periods (Reng et al., 1980). The Songpan-Garze fold system (C) was a platform before the Triassic time, after which it changed rapidly to a foreland basin in the Middle-Late Triassic, and has continued uplifting to a complete land during the Jurassic and Cretaceous periods (Wang et al., 2003).

Our interpretation focuses on wide-angle P-wave reflections from the crystalline crust, the Moho and the upper mantle. We use a finite-difference traveltime inversion method to constrain the P-wave velocity structure above the crystalline basement, and the Raylnvr inversion technique to invert for the velocities and the reflector depths jointly for 2-D models. We further adjust the velocity models by means of synthetic seismograms and the best-fitting Bouguer gravity anomalies. Finally, we discuss the geodynamic implication of the velocity models in the study area.

\section{Reflection/refraction events and velocity model building}

As shown in Fig. 1, the four deep seismic soundings were performed along different azimuths and lengths within the spatial window $22.0-27.8^{\circ} \mathrm{N}, 98.1-103.7^{\circ} \mathrm{E}$. The SW-NE profiles Zhefang-Binchuan (ZF-BC) and Menglian-Malong (MEL-MAL) are 307 and $582 \mathrm{~km}$ long, respectively. The Eryuan-Jiangchuan (EY-JCH) profile, with azimuth nearly NW-SE, has 
a length of $348 \mathrm{~km}$. The Simao-Zhongdian (SM-ZD) profile, the longest one with azimuth nearly N-S, is $607 \mathrm{~km}$ in length. Up to four shots were fired at different sites along each profile, except for the longer profiles where the number of shots were 5 and 8 (Table 1). Each shot was in a hole drilled at variable depth of 11-30 m and loaded with 1,500 to 3,000 kg explosive charge to be detonated. A total of 85 portable single vertical-component analogue seismometers were installed in the area. The propagating seismic phases were recorded with an average station spacing of $2-4 \mathrm{~km}$ at distances as far as $170 \mathrm{~km}$ or even $200 \mathrm{~km}$ from the shot site.

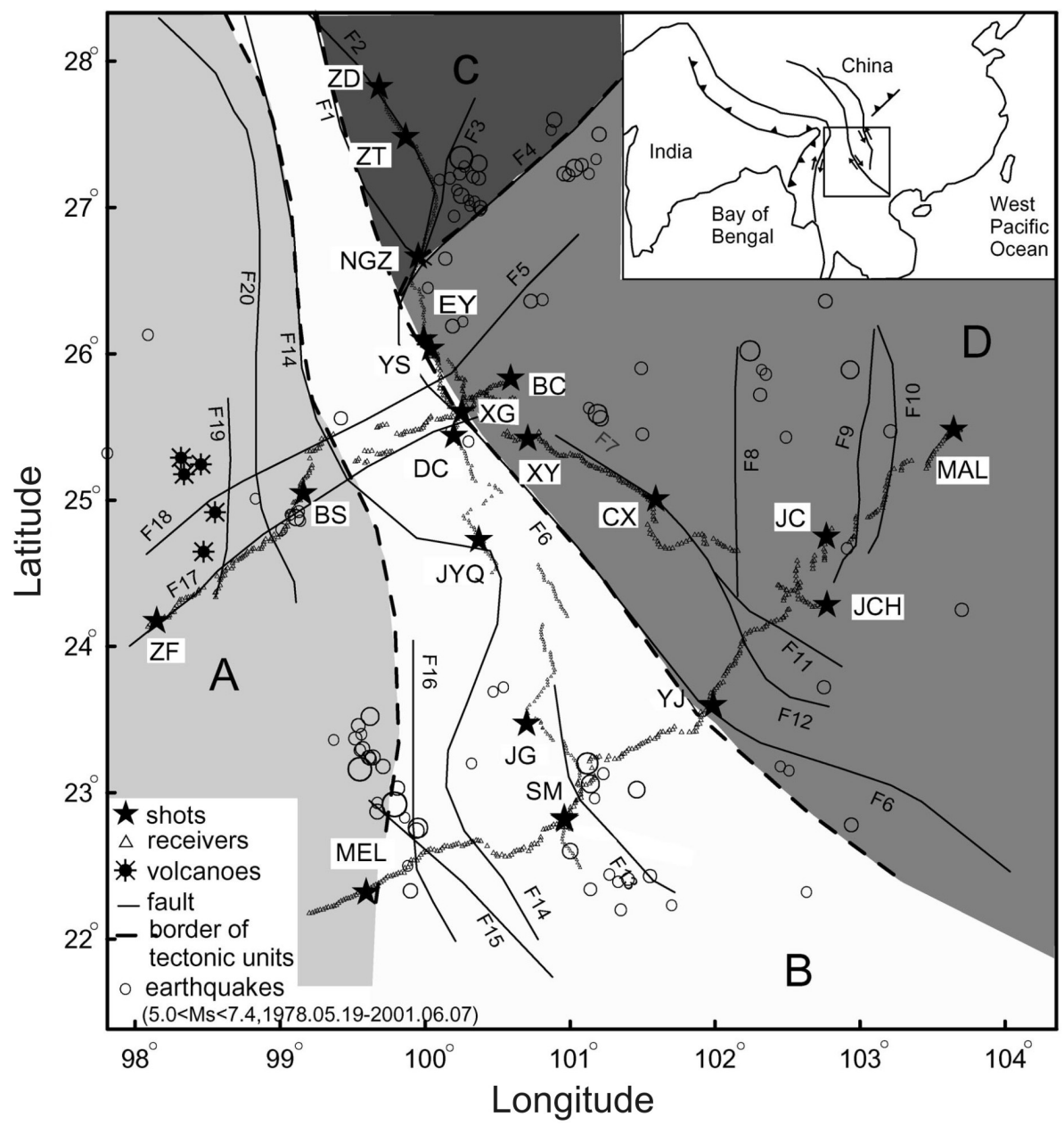

Fig. 1. Surface geology sketch of the Yunnan region. Major areas (shaded zones, in capital letters): A, Tibet-Yunnan fold system; B, Indochina fold system; C, Songpan-Garze fold system; D, Yangtze platform. The inset in the top right corner indicates the location of the study area, outlined by a rectangular window, with respect to the rest of the southern part of the Asian continent. Four wide-angle seismic profiles are plotted with indication of their respective shot points (black stars) and receivers (small triangles).

Key to symbols: F1, Jingsajiang fault; F2, Zhongdian fault; F3, Jianchuan fault; F4, Lijiang-Ninglang fault; F5, Jinghe-Erhai fault; F6, Red River fault; F7, Chuxiong-Tonghai fault; F8, Pudu River fault; F9, west branch of the Xiaojiang fault; F10, east branch of the Xiaojiang fault; F11, Qujiang fault; F12, Jianshui fault; F13, Wuliang Mountain fault; F14, Lanchangjiang fault; F15, Jinghong fault (Menglangba fault); F16, Changning-Shuangjiang fault; F17, Longling fault; F18, Yingjiang-Lianghe fault; F19, Tengchong fault; F20, Nujiang fault. Volcanoes existing in the area (marked by sunlights) are all grouped westwards. Epicentral locations of earthquakes, 5.0 $\leq \mathrm{Mb} \leq 7.4$, occurred during the period 29.05.197807.06.2001 are presented by circles of different size.

Codes for emplacements are as follows: ZD, Zhongdian; ZT, Zhiti; NGZ, Nangaozhai; YS, Yousuo; DC, Dacang; JYQ, Jingyunqiao; JG, Jingu; SM, Simao; EY, Eryuan; XY, Xiangyun; CX, Chuxiong; JCH, Jiangchuan; ZF, Zhefang; BS, Baoshan; XG, Xiaguan; BC, Binchuan; MEL, Menglian; YJ, Yuanjiang; JC, Jincheng; MAL, Malong. 
Table 1. Profiles, total lengths, shot sites and emplacements. Signs denote directions of the profiling: normal (+) and inverse (-).

\begin{tabular}{|c|c|c|}
\hline Profiles & Shots & Site $(\mathrm{km})$ \\
\hline \multirow{5}{*}{$\begin{array}{l}\text { Zhefang-Binchuan } \\
\qquad(307 \mathrm{~km})\end{array}$} & Zhefang & $0.000+$ \\
\hline & \multirow{2}{*}{ Baoshan } & $141.093-$ \\
\hline & & $141.093+$ \\
\hline & Xiaguan & $265.238-$ \\
\hline & Binchuan & $307.039-$ \\
\hline \multirow{6}{*}{$\begin{array}{l}\text { Eryuan-Jiangchuan } \\
\qquad(348 \mathrm{~km})\end{array}$} & Eryuan & $0.000+$ \\
\hline & \multirow{2}{*}{ Xiangyun } & $103.876-$ \\
\hline & & $103.876+$ \\
\hline & \multirow{2}{*}{ Chuxiong } & $200.882-$ \\
\hline & & $200.882+$ \\
\hline & Jiangchuan & $344.961-$ \\
\hline \multirow{9}{*}{$\begin{array}{l}\text { Menglian-Malong } \\
\quad(582 \mathrm{~km})\end{array}$} & \multirow{2}{*}{ Menglian } & $43.428-$ \\
\hline & & $43.428+$ \\
\hline & \multirow{2}{*}{ Simao } & $194.992-$ \\
\hline & & $194.563+$ \\
\hline & \multirow{2}{*}{ Yuanjiang } & $326.830-$ \\
\hline & & $326.830+$ \\
\hline & \multirow{2}{*}{ Jincheng } & $462.420-$ \\
\hline & & $462.420+$ \\
\hline & Malong & $580.972-$ \\
\hline \multirow{13}{*}{$\begin{array}{l}\text { Simao-Zhongdian } \\
\quad(607 \mathrm{~km})\end{array}$} & Simao & $37.639+$ \\
\hline & \multirow{2}{*}{ Jinggu } & $115.316-$ \\
\hline & & $115.316+$ \\
\hline & \multirow{2}{*}{ Jingyunqiao } & $258.385-$ \\
\hline & & $258.385+$ \\
\hline & \multirow{2}{*}{ Dachang } & $339.097-$ \\
\hline & & $339.097+$ \\
\hline & \multirow{2}{*}{ Youshuo } & $406.932-$ \\
\hline & & $406.932+$ \\
\hline & \multirow{2}{*}{ Nangaozhai } & $476.513-$ \\
\hline & & $476.513+$ \\
\hline & Zhiti & $566.813-$ \\
\hline & Zhongdian & $\frac{566.813+}{607.760-}$ \\
\hline
\end{tabular}

We have re-digitized the seismic records at a sampling rate of $5 \mathrm{~ms}$. As shown from the example shot records (Fig. 2) selected from the four wide-angle seismic profiles, the P-wave energy is clearly visible on the record sections up to offsets exceeding $200 \mathrm{~km}$. In Fig. 2, seismic traces of crustal phases are plotted at a reduced traveltime scale using a common reduction velocity of $6.0 \mathrm{~km} / \mathrm{s}$.

The Pg phase, the refracted P-wave from the crystalline upper crust, is the first arrival observed up to a distance of $100 \mathrm{~km}$ for most of the shots. An average velocity of 5.8-6.2 $\mathrm{km} / \mathrm{s}$ is derived directly from the records. The Pg traveltimes are delayed for offsets of 70 $90 \mathrm{~km}$ on the east branch of the Baoshan shot, 110-140 km on the north branch of the Jiangchuan shot, 30-60 km on the east branch of the Menglian shot, and $82-105 \mathrm{~km}$ on the north branch of the Dacang shot. As observed from Fig. 2, the opposite happens at other times: the Pg traveltimes are earlier for offsets $30-50 \mathrm{~km}$ on the east branch of the Zhefang shot, $50-100 \mathrm{~km}$ on the west branch of the Binchuan shot, $85-105 \mathrm{~km}$ on the south branch of the Eryuan shot, $22-34 \mathrm{~km}$ on the east branch of the Menglian shot and $80-120 \mathrm{~km}$ on 
the south branch of the Zhongdian shot. These traveltimes indicate strong lateral variations in P-wave velocity in the upper crust.

Based on seismic records, we are able to identify P-wave energy arrivals corresponding to reflected phases above the crystalline basement and from the crust-mantle discontinuity. Phase $\mathrm{P}_{2}$ within the upper crust is identified at offsets $20-80 \mathrm{~km}$, with an average velocity of $5.7-$ $5.9 \mathrm{~km} / \mathrm{s}$ and coming from a reflector at depths $9.5-19.5 \mathrm{~km}$, though its amplitude is relatively low. [Note Reflection $\mathrm{P}_{1}$ corresponding to a reflector in the topmost part of the crust is generally too low to be detected on most records, and thus is not considered in this study.]
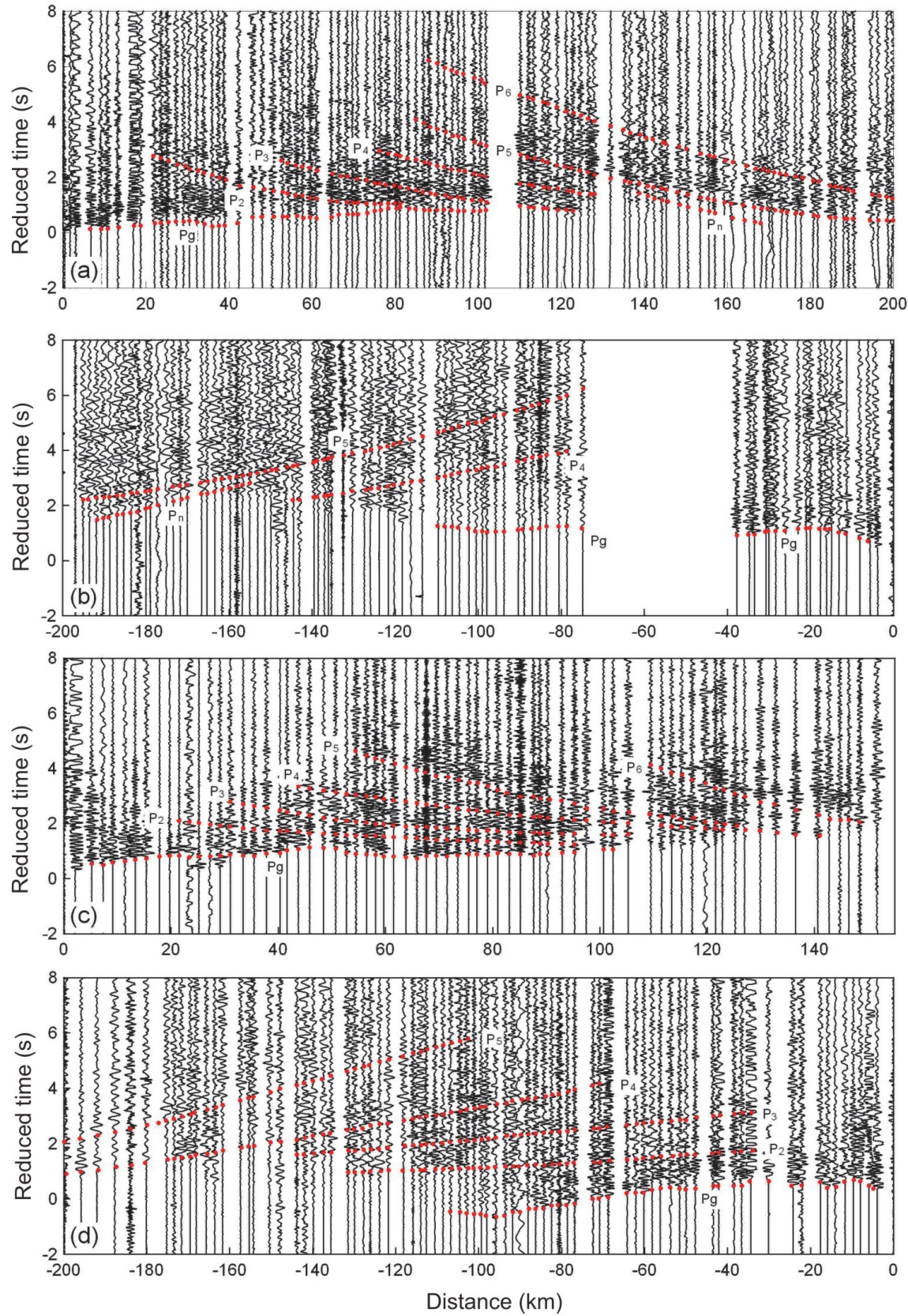

Fig. 2. Four example shot records selected from the four wide-angle seismic profiles respectively. (a) Pphases registered by the Zhefang-Binchuan profile (ZF-BC in Fig.1) with shot fired at ZF. (b) P-phases registered by the Eryuan-Jiangchuan profile (EY-JCH in Fig.1) with shot fired at JCH. (c) P-phases registered by the Menglian-Malong profile (MEL-MAL in Fig.1) with shot fired at MEL. (d) P-phases registered by the Simao-Zhongdian profile (SM-ZD in Fig.1) with shot fired at SM. Each record is plotted with a reduction velocity of $6.0 \mathrm{~km} / \mathrm{s}$. 
Reflection $\mathrm{P}_{3}$ comes from the bottom of the upper crust. It shows relatively high amplitude and can be correlated at large offsets in all shots. The traveltime data can be matched by a model layer with a mean velocity of $5.8-6.0 \mathrm{~km} / \mathrm{s}$, whose layer boundary ranges from 16 to $24 \mathrm{~km}$ in depth.

The low-amplitude reflection $\mathrm{P}_{4}$ is from the bottom of the middle crust, and cannot always be observed. For instance, it is difficult to identify on the west branches of the Binchuan and Jincheng shots and on the north branches of the Xiangyun and Youshuo shots. This phase is generally weaker than reflections $\mathrm{P}_{3}$ and $\mathrm{P}_{5}$. The average velocity is 5.9-6.1 $\mathrm{km} / \mathrm{s}$, and the correspondent reflector depth is $26-33 \mathrm{~km}$.

Reflection $\mathrm{P}_{5}$ is identified as $\mathrm{P}_{\mathrm{m}} \mathrm{P}$, a reflection from the Moho. It can be correlated over an offset of $200 \mathrm{~km}$ for most of the shots. Sometimes this phase is a high-amplitude event and can be well identified on the record sections. However, it is poorly observed on the west branch of the Baoshan shot and on the north branch of the Zhiti shot, due to a small velocity contrast near the Moho discontinuity (Fig. 2).

Pn is the head wave refracted from the uppermost part of the lithospheric mantle. This event features low amplitudes, when compared to other P-wave reflection/refraction events in the crust and upper mantle. However, the onsets are sufficiently clear to be recognised and correlated at distances of 160-260 km on shot records fired at Zhefang, Xiaguan, Eryuan, Simao, and Zhongdian etc (Fig. 2). The analysis of this phase reveals that the P-wave velocity varies rapidly in the deepest part of the crust (Yan et al., 1985; Hu et al., 1986; Kan et al., 1986; Lin et al., 1993). Vp changes rapidly to $7.8 \mathrm{~km} / \mathrm{s}$ and even to a value of $8.0 \mathrm{~km} / \mathrm{s}$ and exceptionally $8.2 \mathrm{~km} / \mathrm{s}$ in the top of the mantle at some locations. The latter emphasizes strong lateral velocity heterogeneity in the uppermost mantle.

A last reflection, denoted as $\mathrm{P}_{6}$, is observed on almost all the shot records. This strong event is interpreted as a reflection from the uppermost mantle. At relatively short distances its average velocity is lower than that of $\mathrm{P}_{5}$. Both events appear nearly parallel at further distances on the record sections. For example, reflection $\mathrm{P}_{6}$ can be seen on the record section of the ZF-BC profile from the shot at Zhefang (Fig. 2a) at offset $\sim 90 \mathrm{~km}$, and likewise on the record section of the MEL-MAL profile from the shot at Menglian (Fig. 2c) at offset $\sim 60 \mathrm{~km}$.

For building the velocity model, we perform the following four steps in sequence.

Step 1: Traveltime inversion using a finite-difference method. The upper crust seismic velocity structure shows a comparatively large lateral variation. We use a finite-difference based traveltime inversion method (Vidale, 1988, 1990; Hole, 1992; Ammon and Vidale, 1993) to invert the Pg data, to obtain the P-wave velocity above the crystalline basement. We initially assume a laterally homogeneous layered medium and invert the picked time-offset curves for 1-D velocity structures at all shots. This 1-D velocity model is an appropriate starting model required for the 2-D velocity inversion to reveal lateral velocity variations.

Step 2: Joint inversion of velocities and depths using the Raylnvr approach. The previous step using only Pg data leads merely to the upper crustal velocity model, but applying the Raylnvr inversion technique we can determine the whole crustal model. This method traces rays in 2-D layered media for rapid forward modelling and inversion of refraction/reflection traveltime data (Zelt and Smith, 1992; Zelt and Forsyth, 1994; Zelt and Barton, 1998; Grad et al., 2003; Maystrenko et al., 2003; Lyngsie et al., 2007). We perform a joint inversion of Pwave velocities and reflector depths in a layer-stripping manner.

Step 3: Adjust models by forward modelling to get best fit to the observed amplitudes and traveltimes. Both velocity discontinuities across layer boundaries and vertical velocity gradients are adjusted by forward modelling for the best possible match with the observed amplitudes and traveltimes. This step, similar to the amplitude modelling described by Zelt and Forsyth (1994), to some extent permits changes to the inverted velocity models. Thus, traveltime inversion and 
waveform modelling are alternated for each layer structure until the best match to both data types is achieved. Synthetics (Fig. 3) reproduce phases consistent with the observed phases (Fig. 2), except for small discrepancies affecting the Pg phase, which may be induced by small-sized velocity anomalies.
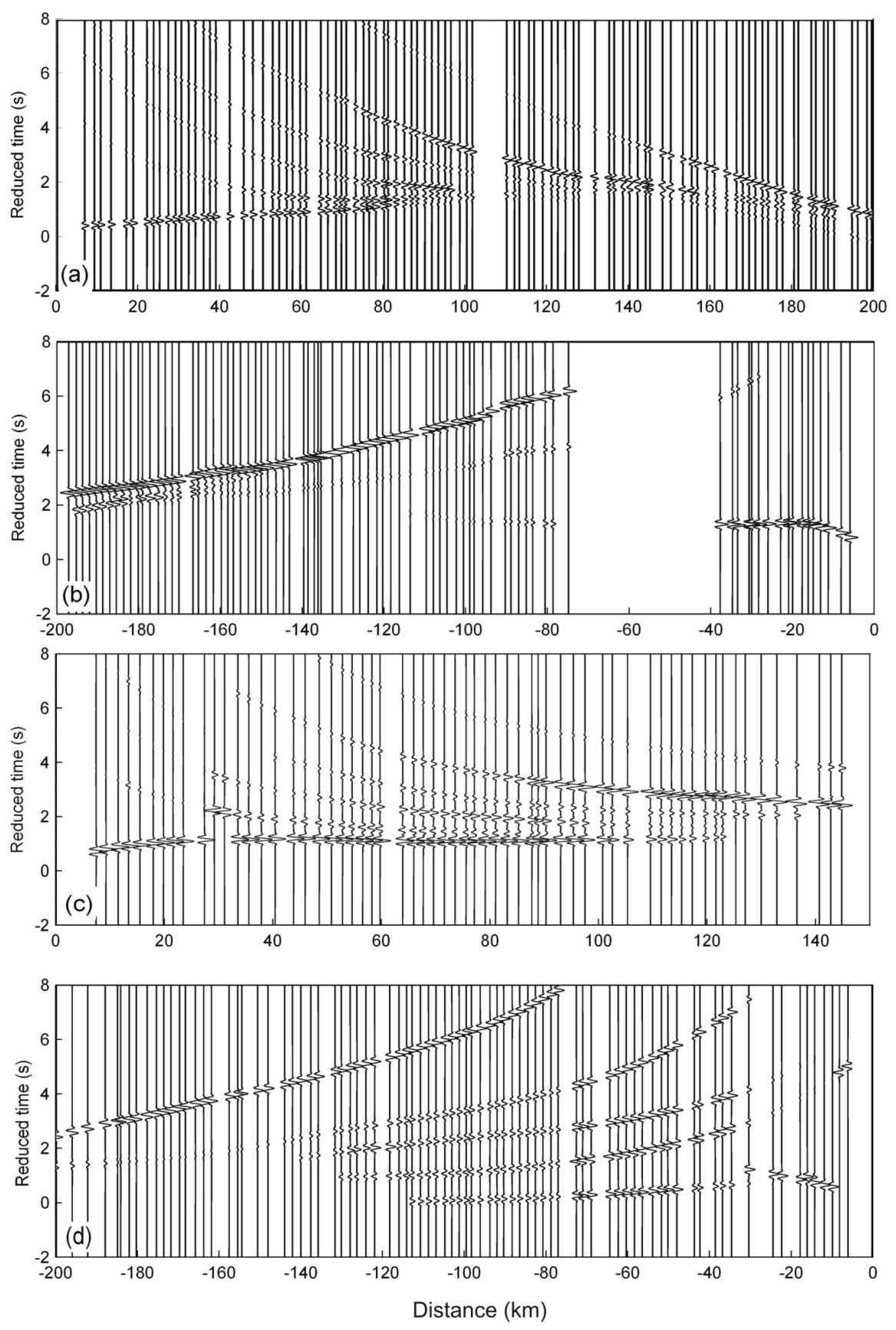

Fig. 3. Synthetic seismograms computed from our final velocity models. (a-d) corresponding to the real shot records (a-d) in Fig. 2. The band-pass filtered P-wave record section is shown with a reduction velocity of $6.0 \mathrm{~km} / \mathrm{s}$.

Step 4: Further improvement of the velocity models by modelling the gravity data. This new model fitting step accounts for the observed gravity data. It also attempts to obtain the best possible match between observed and theoretical Bouguer anomalies. The seismic velocity model is converted to a density model through the relationship given by Ludwig et al. (1970): 


$$
\rho=1.6612 V_{p}-0.4721 V_{p}^{2}+0.0671 V_{p}^{3}-0.0043 V_{p}^{4}+0.000106 V_{p}^{5} .
$$

where $V_{p}$ is the P-wave velocity and $\rho$ is the density. Other relationships such as Sobolev and Babeyko (1994) and Christensen and Mooney (1995) can also be used for this modelling purpose. The Bouguer anomaly is then computed for comparison with the observed gravity anomaly. As shown in Fig. 4, apart from small discrepancies, the fitting with the experimental gravity data is quite good in all cases. The agreement between observed and theoretical gravity anomalies offers us another way to estimate the reliability of our results (Bai et al., 2007). Note that equation (1) is just a simple guide and is not a principal constraint as such.

As an example, Fig. 5 displays the velocity models (of the MEL-MAL profile) obtained after each of these four steps in sequence. Velocities are allowed to vary both laterally and vertically among the six reflectors. The four-step procedure is repeated for each of the four wide-angle seismic profiles.
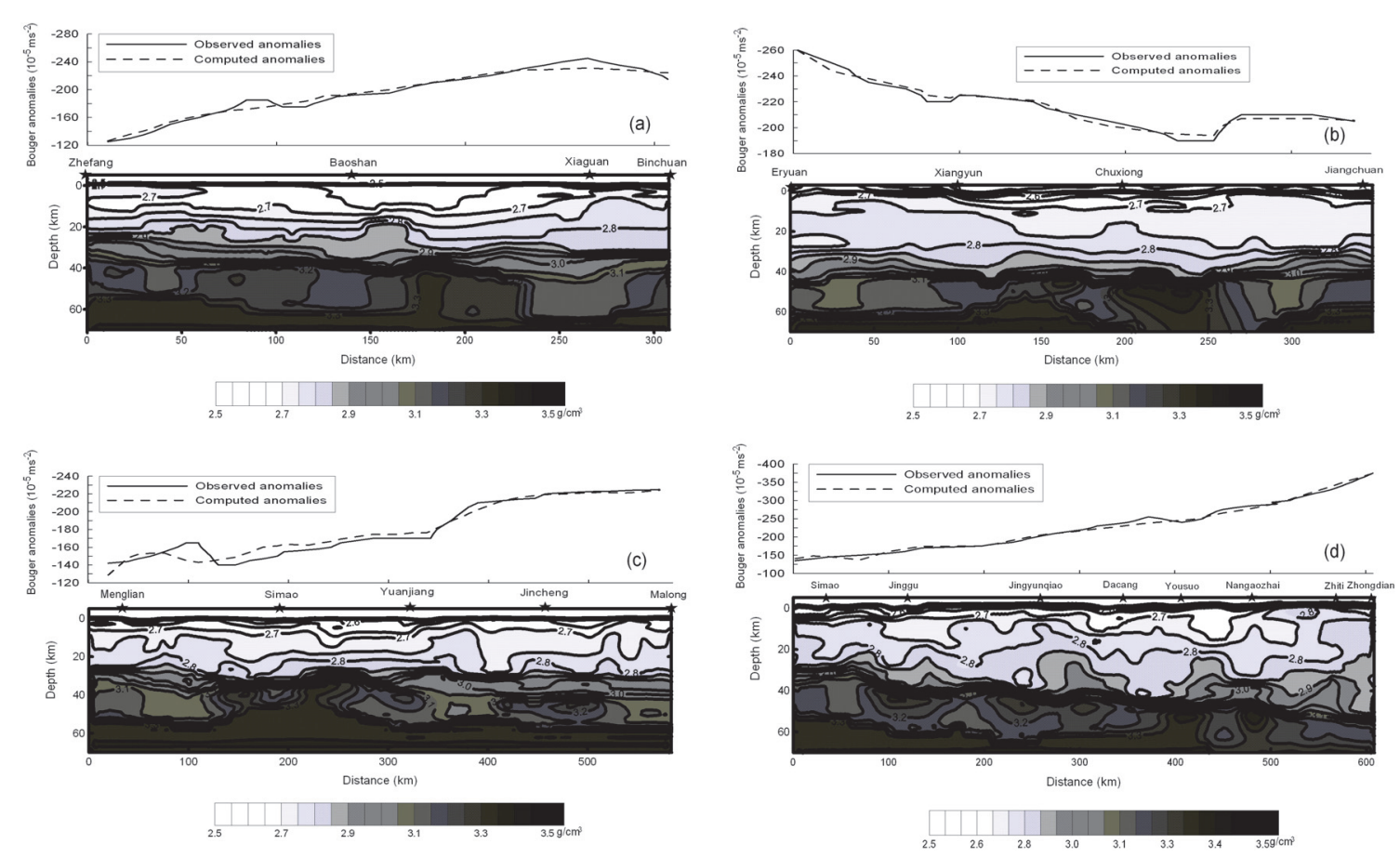

Fig. 4. Density models constructed for the four profiles: (a) Zhefang-Binchuan (ZF-BC in Fig.1), (b) Eryuan-Jiangchuan (EY-JCH), (c) Menglian-Malong (MEL-MAL), and (d) Simao-Zhongdian (SMZD). constructed from the previous 2-D velocity models according to the velocity-density relationship of Ludwig et al. (1970). Density ranges from 2.5 to $3.5 \mathrm{~g} / \mathrm{cm}^{3}$ in all cases. After computing the theoretical gravity anomaly curves, which are given in $10^{-5} \mathrm{~m} / \mathrm{s}^{2}$, the goodness of the fit between observed (continuous lines) and computed (dash lines) Bouguer anomalies along the four profiles of reference supplies information about the accuracy of the results.

\section{Crust-upper mantle velocity models}

The four P-wave velocity models finally obtained, displayed in Figs. 6-9c respectively, supply an overall view of the crust-upper mantle structure in Yunnan Province. Based on the most conspicuous regional features of the crust, we can roughly divide it into upper, middle and lower crust. Except for some local anomalies, the upper crust consists of a sedimentary lid with the P-wave velocity generally less than $5.8 \mathrm{~km} / \mathrm{s}$ and a basement layer with the P-wave velocity 
from 5.8 to $6.2 \mathrm{~km} / \mathrm{s}$ lying at a depth of $17-25 \mathrm{~km}$ (Figs. 6-9c). In the middle and lower crusts, the P-wave velocity ranges from about 6.2 to $6.6 \mathrm{~km} / \mathrm{s}$ and from 6.6 to $7.4 \mathrm{~km} / \mathrm{s}$, respectively, down to $26-33 \mathrm{~km}$ and $34-56 \mathrm{~km}$. The velocity structure beneath the EY-JCH profile is slightly different as the correspondent velocity value is nearly $0.2 \mathrm{~km} / \mathrm{s}$ less than those reflected by the other three profiles.
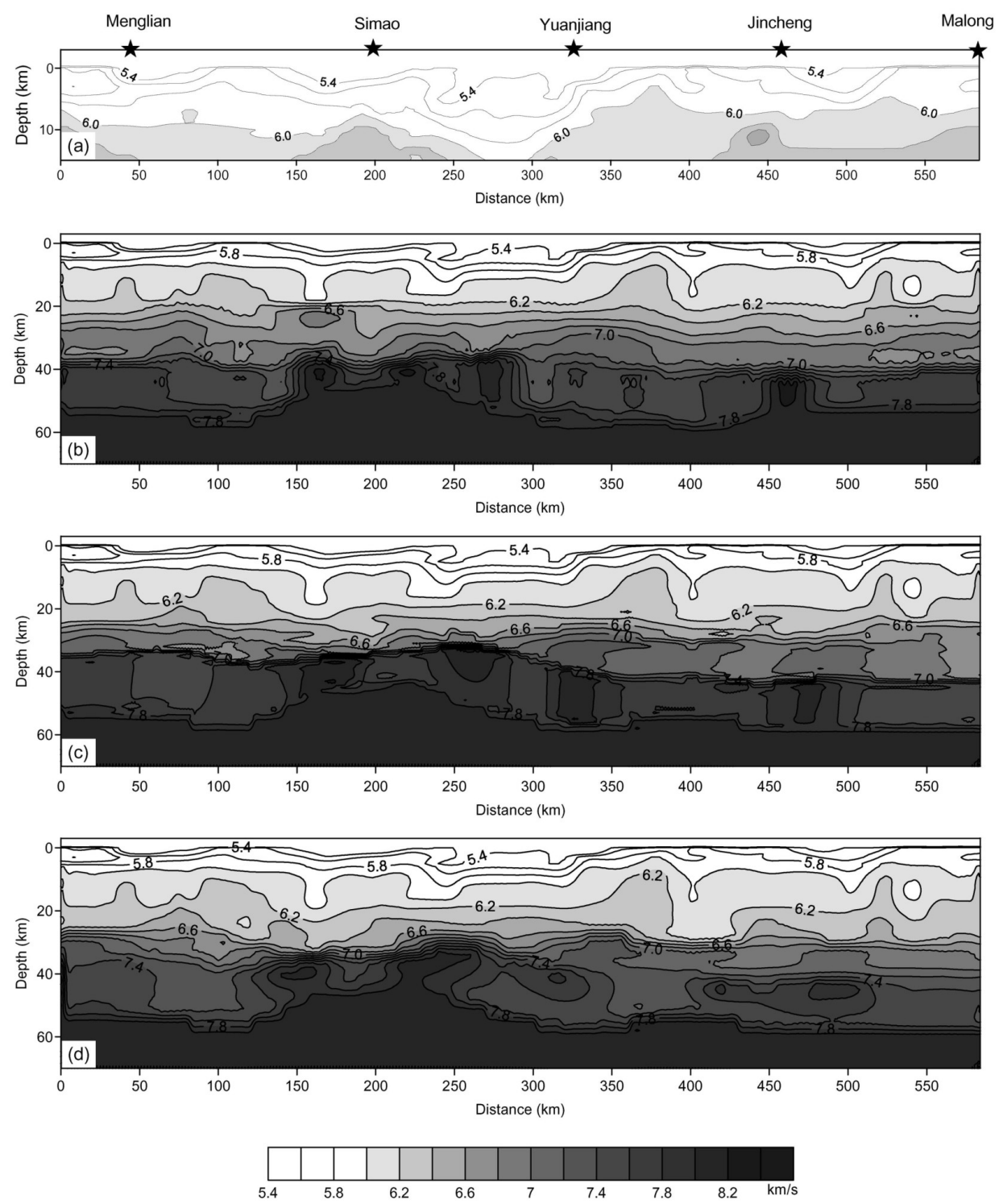

Fig. 5. An example profile (MEL-MAL in Fig. 1) for velocity model building in four steps: (a) traveltime inversion by finite differences, (b) joint inversion of velocities and depths using the Raylnvr inversion,(c) adjust the model by forward modelling to get best fitting to the observed travel times, and (d) further improve the model by gravity data fillting. P-wave velocity isolines are labelled in $\mathrm{km} / \mathrm{s}$.

Lateral heterogeneity in the P-wave velocity is mainly embodied in the lower crust. The Pwave velocity beneath the ZF-BC profile varies generally in the range $6.8-7.4 \mathrm{~km} / \mathrm{s}$, but there are low velocity anomalies at offsets $140-170$ and $240-270 \mathrm{~km}$. For the EY-JCH profile, the Pwave velocity in the lower crust ranges in the interval $6.4-7.0 \mathrm{~km} / \mathrm{s}$. Similarly, under the MELMAL profile, the P-wave velocity in the lower crust is about $6.6-7.4 \mathrm{~km} / \mathrm{s}$, but there exist high 
velocity anomalies at offsets $320-380$ and $480-520 \mathrm{~km}$. For the SM-ZD profile, the P-wave velocity in the lower crust changes between 6.6 and $7.4 \mathrm{~km} / \mathrm{s}$, but there are also high velocity anomalies alternating with anomalies of contrary sign at offsets 40-90, 120-160, 270-340, 410500 and $540-580 \mathrm{~km}$. Strong lateral heterogeneity in the P-wave velocity is also observed in the uppermost mantle where the velocity ranges between 7.8 and $8.0 \mathrm{~km} / \mathrm{s}$ (exceptionally $8.2 \mathrm{~km} / \mathrm{s}$ ), and alternatively high and low velocity zones exist under each profile.
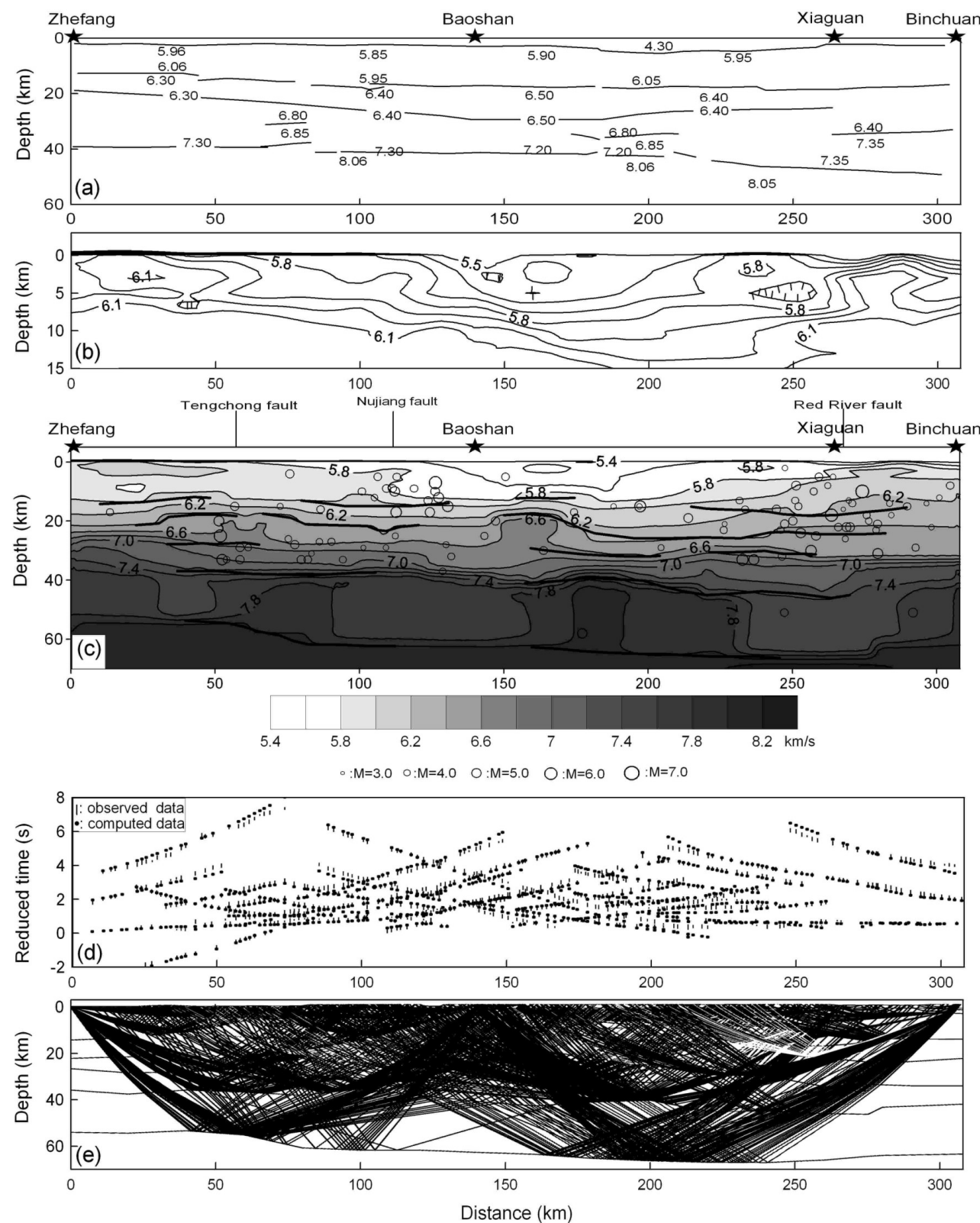

Fig. 6. The P-wave velocity models beneath the Zhefang-Binchuan profile (ZF-BC) proposed successively by different authors, together with the observed and computed travel times in this study and the correspondent ray diagram obtained by ray-tracing: (a) Lithosphere velocity model obtained by Hu et al. (1986); (b) Upper-crust velocity model proposed by Bai and Wang (2003); (c) Final velocity model after this work; (d) observed (short vertical bars) and computed (small black points) travel time data; (e) Ray coverage of the crust underlying the profile. In all cases, velocities are given in $\mathrm{km} / \mathrm{s}$. Shot points (black stars at surface) are pointed out by the names of their respective emplacements. Any seismic event (circles) occurred during the period 1978-2001 at a distance less than $50 \mathrm{~km}$ from the profile has been included in the plot (the size of the circles correlates with the earthquake magnitude). 

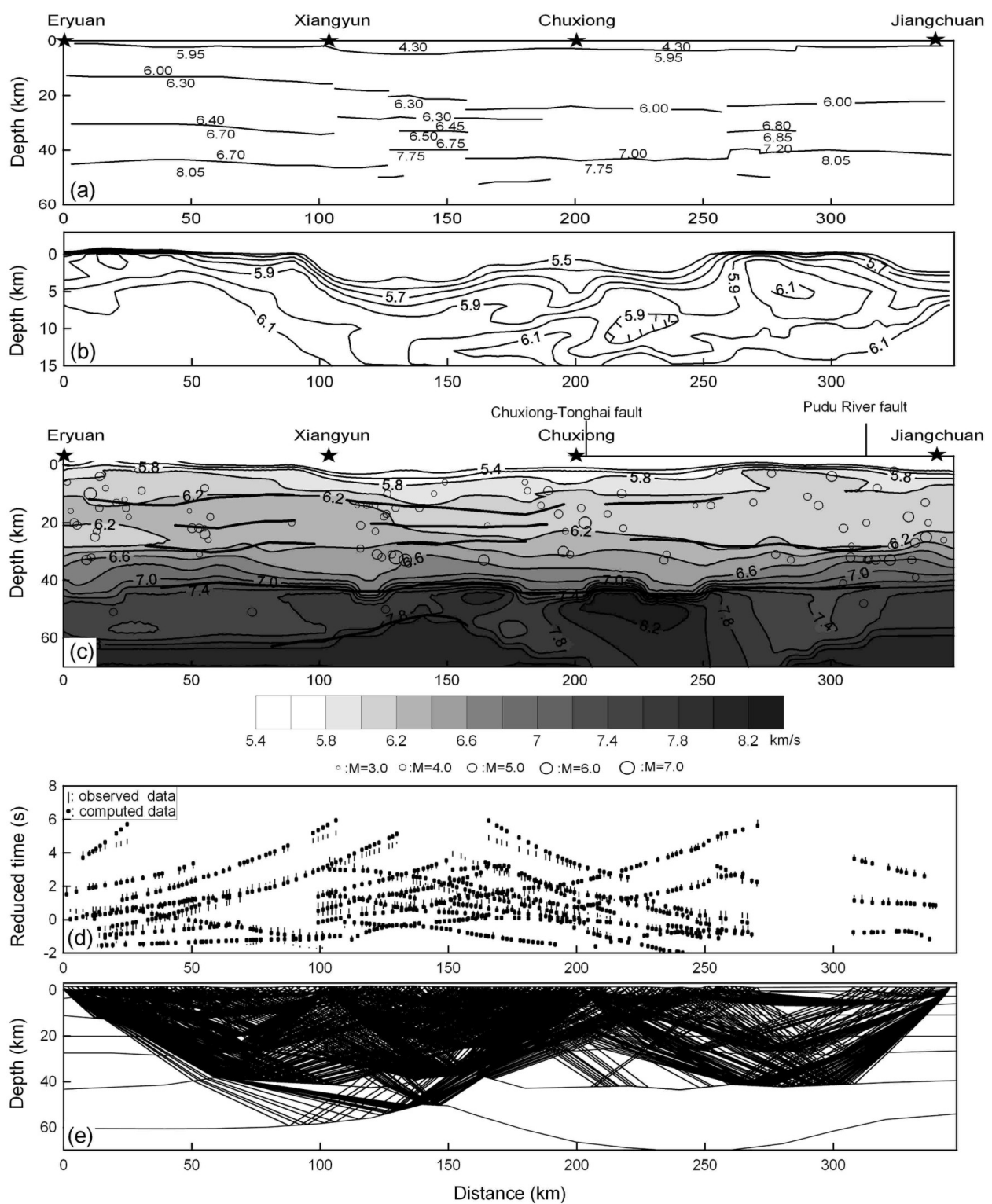

Fig. 7. Layered P-wave velocity models beneath the Eryuan-Jiengchuan profile (EY-JCH). Same legend as Fig. 6.

Boundaries separating all the major crustal layers show an undulating topography at their respective depths, except for the EY-JCH profile whose layering is rather plane horizontal. Similarly, the Moho discontinuity and the uppermost layer of the lithospheric mantle present undulated forms. The Moho, which is the origin of the strong event $\mathrm{P}_{5}$, extends over depths ranging 35-46 km along the ZF-BC profile, $41-45 \mathrm{~km}$ along the EY-JCH profile, $32-45 \mathrm{~km}$ under the MEL-MAL profile and 35-56 km from south to north beneath the SF-ZD profile, the latter being the largest depth fluctuation.

The deepest reflection event $\mathrm{P}_{6}$, detected at subcrustal depths, reveals a strong undulating shape of an inner boundary of the uppermost mantle. This inner boundary ranges at depths 53-63 km along the shortest ZF-BC transect, 52-72 km along the EY-JCH profile, 44-58 $\mathrm{km}$ beneath the MEL-MAL transect and 52-67 km under the longest SF-ZD profile. The most pronounced undulations of this surface arise along the EY-JCH and MEL-MAL profiles (Figs. $7-8 \mathrm{c}$ ). 

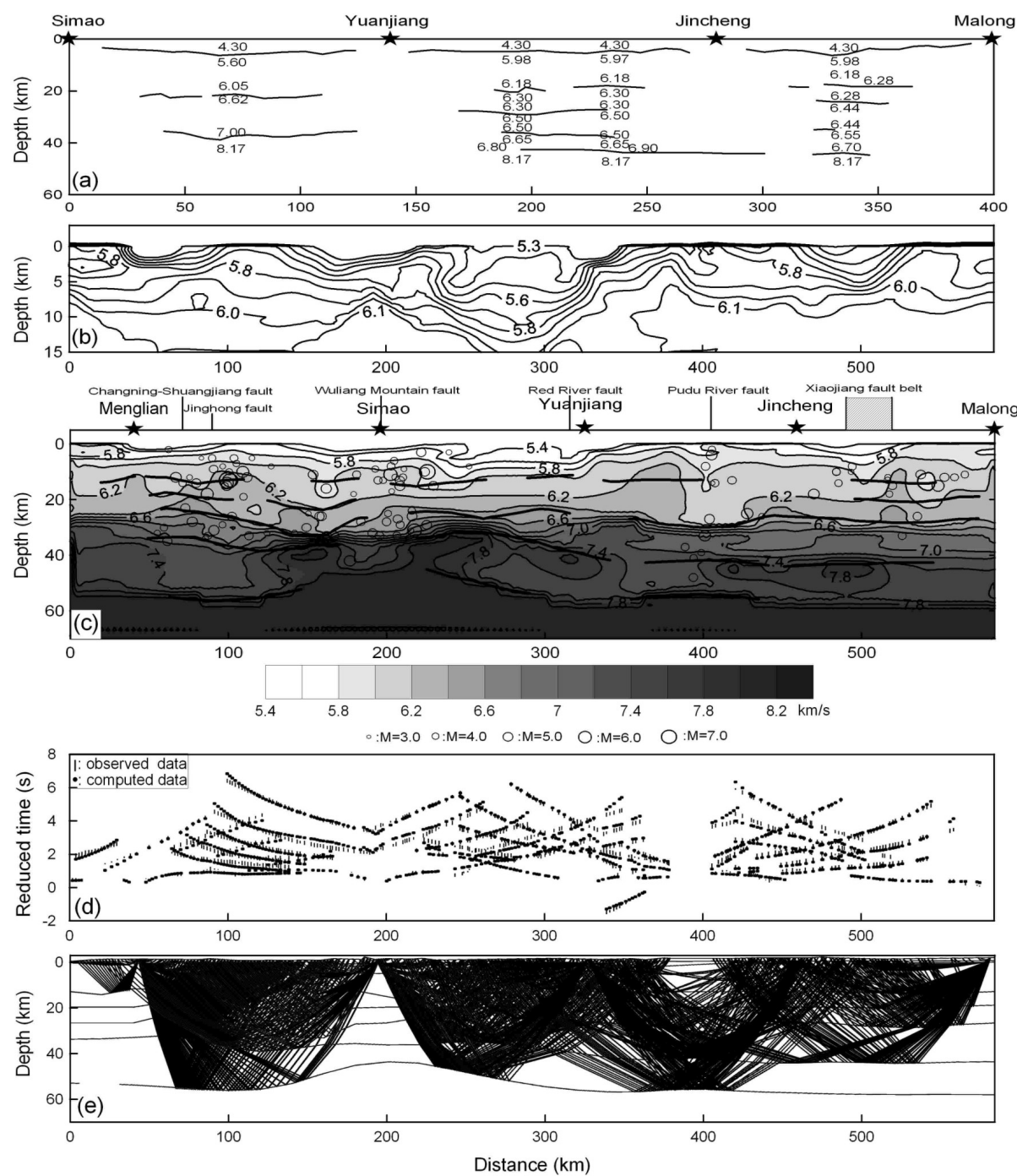

Fig. 8. Layered P-wave velocity models beneath the Menglian-Malong profile (MEL-MAL). Same legend as Fig. 6. It is to be noted that the velocity model (a) after Hu et al. (1986) begins at Simao and the scale for horizontal distance is therefore different.

Although the 2-D models (Figs. 6-9c), obtained in this work using inversion methods, supply detailed structural features both in velocity and in layering, we do see some consistency and similarities to the previous results, for example, the lithosphere model (Figs.6-9a) obtained by Hu et al. (1986) and the upper crust model (Figs. 6-9b) by Bai and Wang (2003). The same major crustal layers at similar depths depict the seismic velocity structure beneath Yunnan. For example, our data reveal that a weak reflection comes from a depth of 11-18 km, in accordance with the results reported by Hu et al. (1986) and Kan et al. (1986) for the ZF-BC and EY-JCH profiles (Figs. 6a and 7a, respectively). The depth 17-25 km given here for the upper crust/middle crust boundary is very close to that (17$25.5 \mathrm{~km}$ ) reported by Lin et al. (1993) for the same boundary along the SM-ZD profile. Except for the SM-ZD profile, we find that the middle/lower crust discontinuity lies generally at a depth of $23-32 \mathrm{~km}$. This also agrees with the results reported by the authors mentioned above. Lastly, the undulated topography of the Moho, which lies approximately at depths between 33 and $48 \mathrm{~km}$ and down to $56 \mathrm{~km}$ under the shot point at Zhongdian (Fig. $9 \mathrm{c})$, agrees with the Moho geometry reported in the early models and particularly by $\mathrm{Hu}$ et al. (1986) (Fig. 9a). 

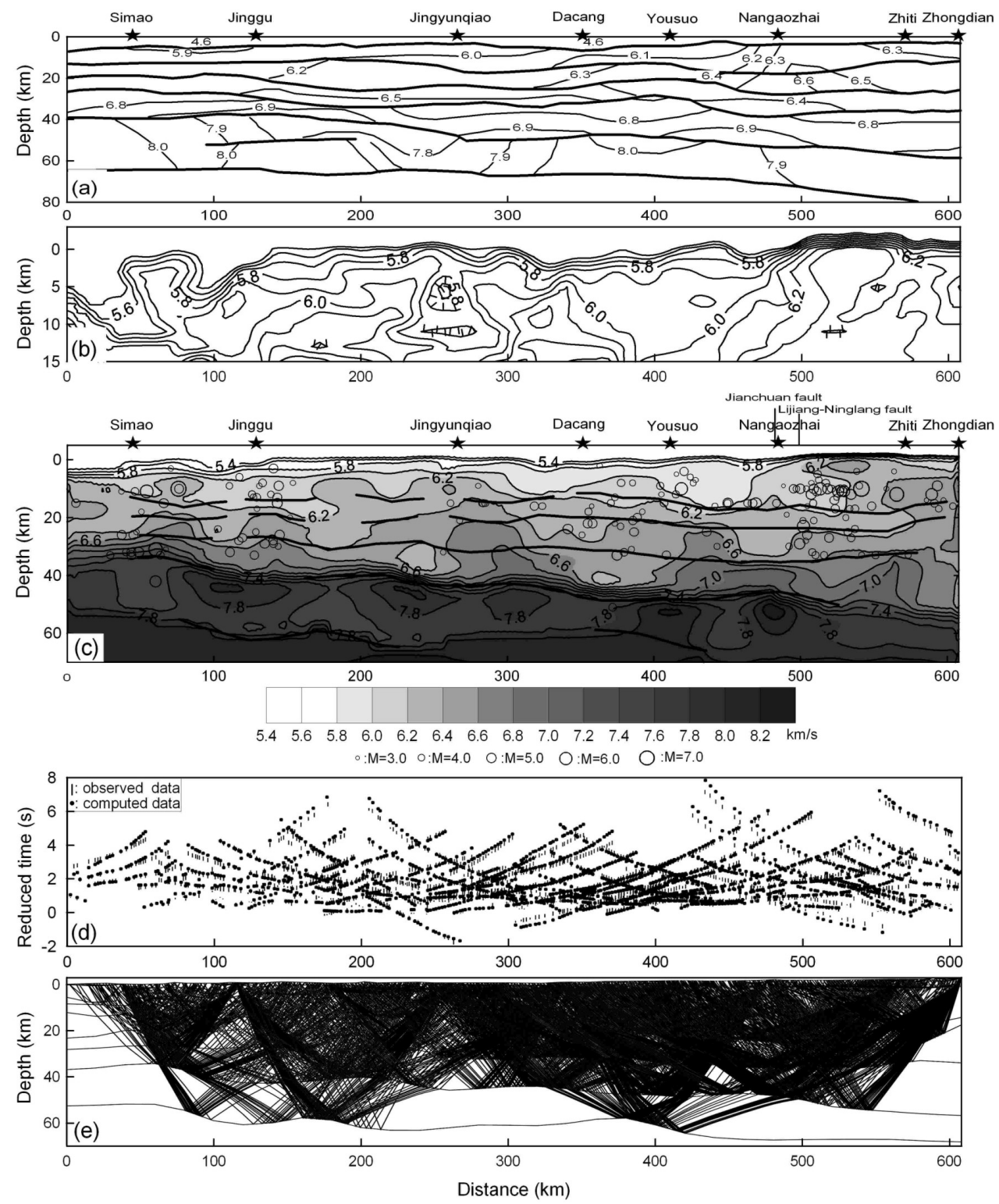

Fig. 9. Layered P-wave velocity models beneath the Simao-Zhongdian profile (SM-ZD). Same legend as Fig.6, although the velocity model represented in the top is due to Lin et al. (1993).

However, the newly derived velocity models reveal more detailed features. For example, the sedimentary cover is a strong, laterally heterogeneous lid, whose boundary may be buried at $8-12 \mathrm{~km}$ depth in some large depressions. A non-horizontal layering is likewise a common feature of the middle and lower crust in the region, and not only of the upper crust. More high and low velocity anomalies are generally disclosed. Some large faults in the area may be related to crustal scale velocity anomalies, which indicates that the Yunnan Province is a typical active area from a geodynamic viewpoint. Moreover, another common feature of the lithospheric mantle as a whole is the rather low P-wave velocity, perhaps due to an excess of temperature in the mantle materials.

Table 2 lists the phases registered by each wide-angle seismic profile, as well as the respective number of traveltime readings, RMS time and fitting index $\chi^{2}$. In particular, the fitting index $\chi^{2}$ is used to check the validity of the crustal P-wave velocity models: the closer $\chi^{2}$ is to 1 , the more reliable are the velocities (Zelt, 1994). A relatively large index $\chi^{2}$ might be due to several factors: deviation of shots and receivers from a linear arrangement; nonnegligible errors made when picking arrivals from the record sections; a deficient model 
parameterization used to specifically define the fine structure of the crust and upper mantle; and an unsuitable damping factor to carry out the inversion. Keeping the best-fitting restriction, the velocity and depth results in the inversion process are averaged to obtain a smooth model. For most cases $(82 \%)$ of the recorded P-wave phases the values of $\chi^{2}$ is rather small (towards 1.0 ).

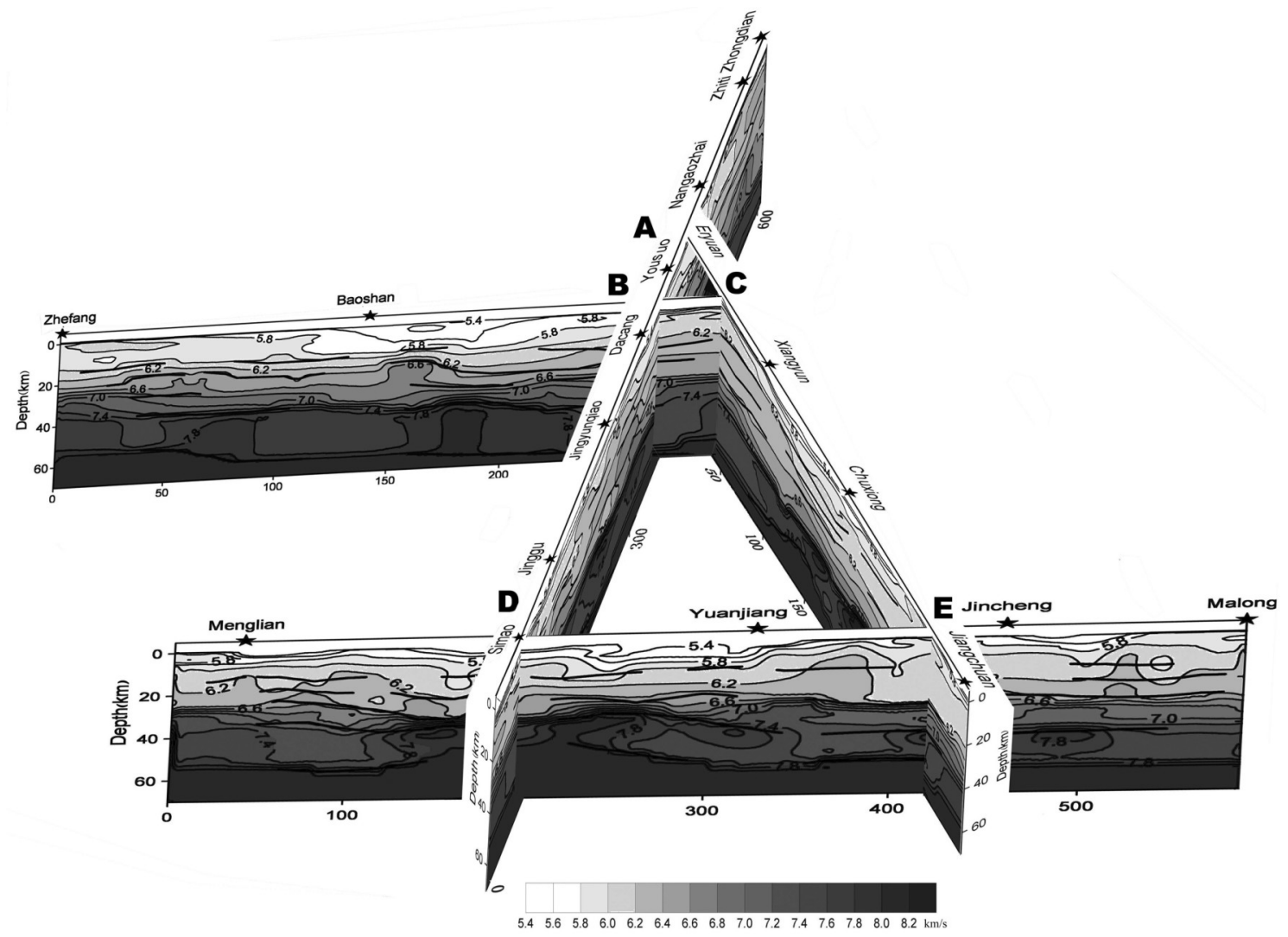

Fig. 10. Fence-frame reconstructed from the previous P-wave velocity models, which provides an overall view of the seismic velocity structure beneath Yunnan divided into upper crust, middle crust, lower crust, Moho discontinuity and lithospheric mantle. Numbers are velocity values in $\mathrm{km} / \mathrm{s}$. The four wide-angle seismic profiles crossing the region intersect in five points that are marked by capital letters.

The comparison in Figs. 6-9d shows a good fitting between times of all correlated phases.

Figs. 6-9e show the illumination of the crust by seismic rays along the four profiles of reference: the ray coverage is in general satisfactory for all of them and the different markers are all correctly illuminated, except for the upper mantle phase. There is only limited ray coverage of the mantle interface which makes it difficult to justify that this phase is a reflection from the same level in all shot-gathers. The ray coverage in Figs 8e and 9e indicates that the undulations of this interface are mostly a result of the interpolation.

\section{Geodynamic implications}

Given the crust/upper mantle velocity models (Figs. 6-9c), we now analyse the geodynamic implications beneath Yunnan Province. A 3D view was obtained when we constructed a fence diagram using the four wide-angle velocity models (Fig. 10). Furthermore, some key features can be stated by analyzing the 1-D velocity depth functions at five intersection point (Fig. 11). 
Differences in the seismic velocity along different azimuths within the upper-middle crust are indeed very small, but the differences within the lower crust and upper mantle are relatively large. The large velocity difference with azimuth is evidence for relatively strong anisotropy at these depths. We estimated $1.6 \% \mathrm{P}$-wave anisotropy for the upper/middle crust and a $4.4 \% \mathrm{P}-$ wave anisotropy for the lower crust and upper mantle. This suggests that the surface deformation in Yunnan area does not extend to the lower crust and is decoupled from the lower crustal and upper mantle flow (Leigh et al., 1997).

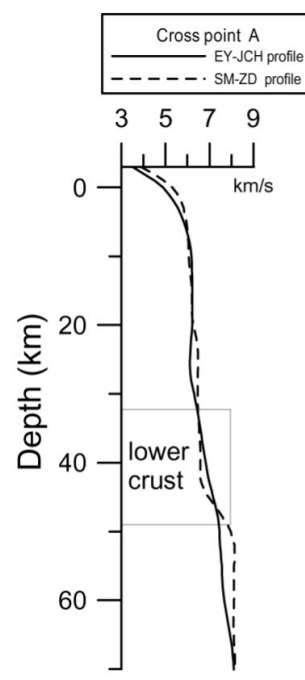

(a)

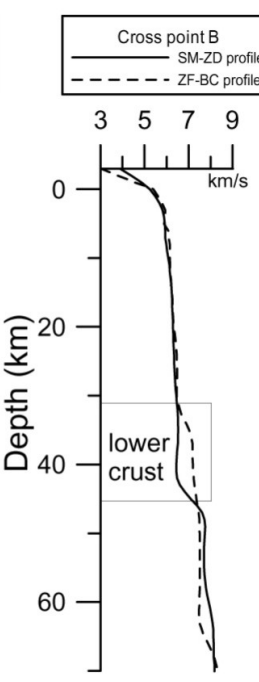

(b)
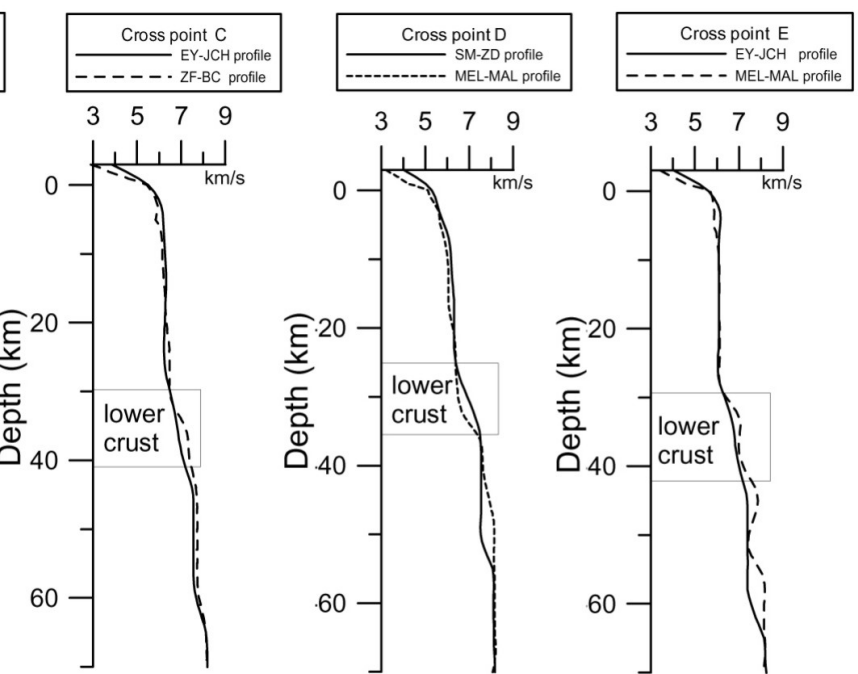

(d)

(e)

Fig. 11. P-wave velocity-depth functions beneath the five cross points (A, B, C, D and E in Fig. 10) where the four seismic profiles intersect in the Yunnan area. In all cases, both the location of the lower crust and its thickness are given.

We may assume that different rheology attributes to the velocity discrepancy versus azimuth. The results suggest a dominant north-south flow within the lower crust and uppermost mantle (EY-JCH and SM-ZD profiles) rather than an east-west one. Such a prevailing flow regime agrees with contemporary tectonic deformation (Wang et al., 2002). The displacement in the northwest-southeast direction is larger than in any other direction. This also provides evidence for the rotation of the lower crust and upper mantle around the east Himalayan foreland.

Seismic velocities beneath the EY-JCH profile are lower than in other cases. The middle and lower crust show velocity values ranging mainly in the intervals $6.2-6.4$ and $6.4-7.0 \mathrm{~km} / \mathrm{s}$ (Fig. 7c), respectively, and for the same crustal depths the velocity values vary in the ranges $6.2-6.6$ and $6.6-7.4 \mathrm{~km} / \mathrm{s}$ in the other three profiles (Figs. 6c, 8c and 9c). These low velocities can be clearly seen in Figs $11 \mathrm{c}$ and $11 \mathrm{e}$, and are probably due to the presence of heat coming from the mantle, which would lead to a large-scale melting of deep rocks. This is highly consistent with the results given by Wang et al. (2003), which detected low-velocity anomalies at depths of 30 and $50 \mathrm{~km}$. Low seismic velocities underneath tectonic plates are commonly attributed to the presence of melt (Hammond and Humphreys, 2000; Dunn and Forsyth, 2003). However, geochemical observations suggest that the amount of melt in this area is only about $0.1 \%$ (McKenzie, 1985; Strake et al., 2003), which is too small to produce a significant decrease in seismic velocities. Hence our interpretation is that in the area the seismic velocity is more strongly affected by temperature than by the presence of a low percentage of melt (Priestley and McKenzie, 2006). 
Large number of faults cross the study area, which is a seismically active zone, as indicated in Fig. 1 by the epicentral locations of the earthquakes (magnitude 5.0-7.4). The orthogonal projections of these locations (checked from the Chinese Earthquake Network Center, the International Seismological Center, and the National Earthquake Information Center catalogues) can be seen in Figs. 6-9c. The projection distances are lesser than $50 \mathrm{~km}$ from the respective profiles.

Table 2. Profiles, identified seismic phases, respective number of travel time data, root-mean-square (RMS) time residuals and fitting index.

\begin{tabular}{|c|c|c|c|c|}
\hline Profile & Phase & Number of data & RMS time (s) & Fitting index $\chi^{2}$ \\
\hline \multirow{7}{*}{ Zhefang-Binchuan } & $\mathrm{Pg}$ & 181 & 0.130 & 8.989 \\
\hline & $\mathrm{P} 2$ & 109 & 0.164 & 4.898 \\
\hline & P3 & 127 & 0.184 & 4.438 \\
\hline & $\mathrm{P} 4$ & 71 & 0.127 & 1.504 \\
\hline & P5 & 207 & 0.185 & 3.503 \\
\hline & Pn & 43 & 0.170 & 4.632 \\
\hline & P6 & 161 & 0.266 & 8.286 \\
\hline \multirow{7}{*}{ Eryuan-Jiangchuan } & $\mathrm{Pg}$ & 163 & 0.106 & 15.336 \\
\hline & $\mathrm{P} 2$ & 126 & 0.168 & 3.129 \\
\hline & P3 & 71 & 0.138 & 1.729 \\
\hline & $\mathrm{P} 4$ & 136 & 0.104 & 1.137 \\
\hline & P5 & 202 & 0.226 & 5.415 \\
\hline & $\mathrm{Pn}$ & 69 & 0.207 & 6.895 \\
\hline & P6 & 80 & 0.268 & 7.434 \\
\hline \multirow{7}{*}{ Menglian-Malong } & $\mathrm{Pg}$ & 205 & 0.097 & 10.768 \\
\hline & $\mathrm{P} 2$ & 142 & 0.185 & 3.383 \\
\hline & P3 & 81 & 0.179 & 3.042 \\
\hline & $\mathrm{P} 4$ & 187 & 0.182 & 2.811 \\
\hline & P5 & 220 & 0.226 & 7.511 \\
\hline & $\mathrm{Pn}$ & 33 & 0.147 & 3.610 \\
\hline & P6 & 145 & 0.277 & 8.804 \\
\hline \multirow{7}{*}{ Simao-Zhongdian } & $\mathrm{Pg}$ & 255 & 0.199 & 23.516 \\
\hline & $\mathrm{P} 2$ & 282 & 0.365 & 18.857 \\
\hline & P3 & 354 & 0.176 & 2.746 \\
\hline & $\mathrm{P} 4$ & 406 & 0.226 & 6.722 \\
\hline & P5 & 490 & 0.197 & 4.670 \\
\hline & $\mathrm{Pn}$ & 45 & 0.219 & 10.889 \\
\hline & P6 & 146 & 0.372 & 34.463 \\
\hline
\end{tabular}

Shallow velocity anomalies underneath the Zhefang, Baoshan and Xiaguan shot points of the ZF-BC profile (Fig. 6c) can be correlated with the Tengchong fault, Nujiang fault and Red River fault, respectively. Under the Nujiang fault (F20 in Fig. 1) the velocity contours appear slightly distorted at depths of 5-10 km, just where a concentration of earthquakes with focal depths $5-18 \mathrm{~km}$ is located. This indicates that strain energy may easily accumulate at this place. Similarly distorted velocity contours and seismic activity in the middle and lower crust, coincide at the intersection of the profile with the Red River fault (F6 in Fig. 1), below Xianguan, just where the profile meets the Jinghe-Erhai fault (F5 in Fig.1), and therefore this fault system might be analogously a pathway for the transference of mechanical and thermal energy from the deep interior of the crust. 
Regarding the MEL-MAL profile, remarkable concentrations of earthquakes down to the lower crust can be observed just in the intersections with the Changning-Shuangjiang fault and the Jinhong fault, the Wuliang Mountain fault, and the Pudu River fault (Fig. 8c). This is clearly identified by distorted velocity contours that surround the vertical alignment of earthquake hypocenters.

Velocity anomalies, earthquakes and faulting seem to be coupled. It suggests that probably the strain energy undergoes an accumulation process at those sites in which the velocity contours appear distorted, and the deep faults might play the role of pathways for energy transference from deep levels.

At zones around ancient volcanoes, for instance in the Tengchong area (Tengchong fault, F19 in Fig. 1), once the contemporary volcanic activity stopped, most of the energy that was not released could be transferred to tectonic locations permitting the energy accumulation for further earthquake generation: the Longlin seismic belt (Longling fault, F17 in Fig. 1) is an example. Contrasting with this possibility, at zones free of ancient volcanoes, such as the Lijiang-Ninglang seismic belt (Lijiang-Ninglang fault, F4 in Fig. 1), between Zhiti and Nangaozhai, the occurrence of large earthquakes derives from the stress field and the complex seismotectonic frame of the area revealed by its distorted seismic velocity structure (Fig. 9c).

The Red River strike-slip fault (F6 in Fig. 1) represents the most important tectonic feature of the Yunnan Province (Allen et al., 1984; Tapponnier et. al., 1990). The wide spreading of lava around Yuanjiang ( $\mathrm{YJ}$ in Fig. 1) at the western margin of the Yangtze platform (D in Fig. 1), the centre of the MEL-MAL profile, suggests that this fault might have been the magma pathway from Paleoproterozoic to Triassic, especially in the Permian and Triassic (Wu et al., 1998). The velocity model concerning the ZF-BC profile (Fig. 6c) reveals that this fault is deep and large, penetrating steeply within the middle-lower crust, dipping to the southwest at nearly 60 degrees. This fault system lies at a boundary of high/low velocity contrast (Fig. 6c). The combination of these structural characteristics together with the deposits of lava around Yuanjiang leads us to consider the Red River fault and its branches as the pathway through which the magma rose and could accumulate in earlier epochs.

Yunnan is one of the most seismically active regions in continental China, and also one of the most interesting regions from a geodynamic viewpoint. Although we do not see a remarkable undulation of the Moho, we can see a clear reflection boundary embodied in the lithospheric mantle. In this area, the Pn velocity is generally lower than the global average of $8.09 \mathrm{~km} / \mathrm{s}$ (Christensen and Mooney, 1995). The crust-upper mantle velocity structure appears to feature degrees of lateral heterogeneity. Deep faults related to crustal velocity anomalies seem to be the pathway for mechanical and thermal energy transfer, associated with frequent seismic events and the occurrence of volcanic episodes.

Signs of high velocities in the middle-lower crust, observed earthquake locations combined with deep faults suggest that around some places, e.g. the section between Menglian and Simao (MEL-MAL profile), the lower crust is rigid up to a point permitting the rupture and the release of seismic energy. The strength of this rigid structure is similar to one of the four models of continental lithosphere summarized by Jackson (2002), which is a combination of dry lower crust and wet mantle, so that the movements are mainly driven by the upper mantle and not by the lower crust.

However, this model may not be appropriate for other places where velocity anomalies are unclear and there is a lack of seismic activity within the lower crust. The transect lying north of Dacang, between Youshuo and Nangaozhai (SM-ZD profile profile), might be an example of an alternative combination of wet crust and mantle. There the velocity pattern shows a high velocity anomaly within the middle-lower crust connecting with an anomaly 
of the same sign within the upper mantle. But the lack of earthquake occurrence in the lower crust is evident, which may be interpreted as fluid material penetrating the lower crust such that the fluid action largely decreases the strength. The wet lower crust may be directly attributed to dehydration of metamorphic rocks under high-temperature and highpressure conditions.

The evidence of widespread low velocity $(7.8-8 \mathrm{~km} / \mathrm{s})$ in the uppermost mantle beneath Yunnan might be the result of an episode of upward hot material occurred entirely during the Cenozoic period (Mooney and Braile, 1989). However, there are also high velocities of about $7.2-7.4 \mathrm{~km} / \mathrm{s}$ at the bottom of the crust. This may be matched with the composition of granulate and/or eclogite and attributed to the intrusion of mantle material or remaining patches of ancient oceanic crust, which are represented by a few types of ophiolite suites that are exposed in the region (Zhang and Wang, 2007; Zhang et al., 2008).

Our results permit us to suppose that for the complex actions of subduction, intrusion and interaction exerted by different plates, the lower crust contains 'soft' metamorphic rocks characterized by low seismic velocity, which is a result of heat and fluids, and it also includes mafic or hypermafic 'rigid' ancient oceanic crust, thus exhibiting a remarkable laterally heterogeneous structure. A simple jelly sandwich model is not appropriate for depicting the crustal structure and geodynamics in the Yunnan Province (Jackson, 2002). The major continuous deformation stresses affecting southern China may come from the upper mantle. A quantitative estimate of Pn anisotropy is of importance for the mantle and lower crustal deformation analysis (Bamford, 1977; Scherwath et al., 2002).

\section{Conclusions}

Re-interpretation of four seismic transects in Yunnan, Southwestern China, leads to two main conclusions as follows.

The crust is roughly divided into an upper crust with bottom depth of $17-25 \mathrm{~km}$, a middle crust with bottom depth of $26-33 \mathrm{~km}$, and a lower crust with bottom depth of 33-56 km. The P-wave velocities within these three layers are 5.8-6.2, 6.2-6.6, and $6.6-7.4 \mathrm{~km} / \mathrm{s}$, respectively. Both the rapidly varying seismic velocity in the deepest crust and the undulated Moho show a complex crust/mantle transition with strongly contrasting velocity heterogeneities.

The small velocity difference along different azimuths in the upper-middle crust suggests that the surface deformation in Yunnan area does not extend to the lower crust and is decoupled from the lower crustal flow. However, the P-wave velocity discrepancy of the lower crust and upper mantle beneath profiling cross points leads to a north-south flow. This agrees with contemporary tectonic deformation, and also provides evidence for the rotation of the lower crust-upper mantle medium around the east Himalayan foreland.

\section{Acknowledgments}

The work was supported jointly by Chinese Academy of Sciences (KZCX2-109), Science and Technology Ministry of China (2002CB412604), Natural Science Foundation of China (40304006), and Imperial College London. We are also indebted to C.A. Zelt and J.A. Hole who gracefully supplied us the inversion code Raylnvr and the finite-difference inversion program package, respectively.

\section{References}

Allen, C.R., Gillespie, A.R., Han, Y., 1984. Red River and associated faults, Yunnan Province, China: Quaternary geology, slip rates, and seismic hazard. Bull. Geol. Soc. Am. 95, 686-700.

Ammon, C.J., Vidale, J.E., 1993. Tomography without rays. Bull. Seism. Soc. Am. 83, 509-528. 
Bai, Z.M., Wang, C.Y., 2003. Tomographic investigation of the upper crustal structure and seimotectonic environments in Yunnan province. Acta seismol. Sin. 16(2), 127-139.

Bai, Z.M., Zhang, Z., Wang, Y., 2007. Crustal structure across the Dabie-Sulu orogenic belt revealed by seismic velocity profiles. J. Geophys. Eng. 4, 436-442.

Bamford, D., 1977. Pn-velocity anisotropy in a continental upper mantle. Geophys. J. Roy. Astron. Soc. 49, 29-48.

Christensen, N.I., Mooney, W.D., 1995. Seismic velocity structure and composition of the continental crust: A global view. J. Geophys. Res. 100 (B7), 9761-9788, 1995.

Dunn, R.A., Forsyth, D.W., 2003. Imaging the transition between the region of melt generation and crustal magma chamber beneath the southern East Pacific Rise with short-period Love waves. J. Geophys. Res. 108, 2352-2360.

Grad, M., Gryn, D., Guterch, A., Janik, T., Keller, R., Lang, R., Lyngsie, S.B., Omelchenko, V., Starostenko, V.I., Stephenson, R.A., Stovba, S.M., Thybo, H., Tolkunov, A., 2003. "DOBREfraction'99"-velocity model of the crust and upper mantle beneath the Donbas Foldbelt (East Ukraine). Tectonophysics 371, 81-110.

Hammond, W.C., Humphreys, E.D., 2000. Upper mantle seismic wave velocity: effects of realistic partial melt geometries. J. Geophys. Res. 105, 10975-10986.

Hole, J.A., 1992. Nonlinear high-resolution three-dimensional seismic travel-time tomography. J. Geophys. Res. 97, 6553-6562.

Hu, H. X., Lu, H.X., Wang, C.Y., 1986. Explosion investigation of the crustal structure in Western Yunnan Province. Acta Geophys. Sin. 29(2), 133-144 (in Chinese, with abstract in English).

Huang, J.Q., Cheng, B.W., 1987. The evolution of Tethys in China and adjacent regions. Beijing Geological Press (in Chinese, with abstract in English).

Jackson, J., 2002. Strength of the continental lithosphere: Time to abandon the jelly sandwich? GSA Today 12, 4-9.

Jiang, C.S., 1985. Volcanoes and earthquakes in the Tengchong area, Yunnan Province, China. J. Seismol. Res. 8, 107-120 (in Chinese, with abstract in English).

Kan R.J., Hu, H.X., Zeng, R.S., Mooney, W.D., 1986. Crustal structure of Yunnan Province, P.R. China, from seismic refraction profiles. Science 234, 433-437.

Leigh, H.R., Burchfiel, B.C., King, R.W., Wang, E.C., Chen, Z.L., Shen, F., Liu, Y.P., 1997. Surface deformation and lower crustal flow in eastern Tibet. Science 276,788-790.

Lin, Z.Y., Hu, H.X., Zhang, W.B., Zhang, H.F., He, Z.Q., Lin, Z.M., Qiu, T.X., 1993. Preliminary interpretation of a deep seismic sounding in Western Yunnan. Acta seismol. Sin. 15, 427-440 (in Chinese, with abstract in English).

Ludwig, W.J., Nafe, J.E., Drake, C.L., 1970. Seismic refraction, in: Maxwell, A.E. (ed.), The Sea 4, pp. 53-84, Wiley-Interscience, New York.

Lyngsie, S.B., Thybo, H, Lang, R., 2007. Rifting and lower crustal reflectivity: A case study of the intracratonic Dniepr-Donets rift zone, Ukraine. J. Geophys. Res. 112, B12402, doi: 10.1029/2006JB004795.

Maystrenko, Y., Stovba, S., Stephenson, R., Bayer, U., Menyoli, E., Gajewski, D., Huebscher, C., Rabbel, W., Saintot, A., Starostenko, V., Thybo, H., Tolkunov, A., 2003. Crustal-scale pop-up structure in cratonic lithosphere: DOBRE deep seismic reflection study of the Donbas fold belt, Ukraine. Geology 31, 733-736.

McKenzie, D., 1985. ${ }^{230} \mathrm{Th}-{ }^{238} \mathrm{U}$ disequilibrium and the melting processes beneath ridge axes. Earth Planet. Sci. Lett. 72, 149-157.

Mooney, W.D., Braile, L.W., 1989. The seismic structure of the continental crust and upper mantle of North America, in: Bally, A.W., Palmer, A.R. (eds.), The Geology of North America, An Overview. pp. 39-52, Geological Society of America, Boulder, Colorado.

Priestley, K., McKenzie, D., 2006. The thermal structure of the lithosphere from shear wave velocities. Earth Planet. Sci. Lett. 244, 285-301.

Reng, J.S., Jiang, C.F., Zhang, Z.K., 1980. Tectonics and evolution in China. Beijing Science Press, 124 pp. (in Chinese, with abstract in English).

Scherwath, M., Melhuish, A., Stern, T, and Molnar, P., 2002. Pn anisotropy and distributed upper mantle deformation associated with a continental transform. Geophys. Res. Letters 29(7), 1175, doi: 10.1029/2001GLO14179.

Sobolev, S., Babeyko, A.Y., 1994. Modeling of mineralogical compositions, density and elastic wave velocities in anhydrous magnetic rocks. Surveys in Geophysics 15, 515-544. 
Tapponnier, P, Lacassin, R., Leloup, P.H, 1990. The Ailao Shan/Red River metamorphic belt: Tertiary left-lateral shear between Indo-China and South China. Nature 343, 431-437.

Vidale, J.E., 1988. Finite-difference travel time calculation. Bull. Seism. Soc. Am. 78, 2062-2076.

Vidale, J.E., 1990. Finite-difference calculation of travel times in three dimensions. Geophysics 55, 521-526.

Wang, Q., Zhang, P.Z., Ma, Z.J., 2002. GPS database and velocity field of contemporary tectonic deformation in continental China. Earth Science Frontiers in China 9(2), 415-429 (in Chinese, with abstract in English).

Wang, C.Y., Chan, W.W., Mooney, W.D., 2003. Three-dimensional velocity structure of the crust and upper mantle in Southwestern China and its tectonic implications. J. Geophys. Res. 108, 1315.

Wang, C.Y., Gang, H.F., 2004. Crustal structure in the Tengchong volcano-geothermal area, Western Yunnan, China. Tectonophysics 380, 69-87.

Wu, J.M., Huang, Y.P., Liu, Z.C., 1998. Formations and ore-controlling characteristics of the marine volcanic rocks on the western margin of the Yangtze platform. Mineral Deposits 17(4), 321-330 (in Chinese, with abstract in English).

Yan, Q.Z., Zhang, G.Q., Kan, R.J., 1985. The crustal structure of the Simao-Malong Profile, Yunnan Province, China. J. Seismol. Res. 8(2), 249-264 (in Chinese, with abstract in English).

Zelt, C.A., Smith, R.B., 1992. Seismic travel time inversion for 2-D crustal velocity structure. Geophys. J. Int. 108, 16-34.

Zelt, C.A., Forsyth, D.A., 1994. Modelling wide-angle seismic data for crustal structure: Southeastern Grenville Province. J. Geophys. Res. 99, 11687-11704.

Zelt, C.A., Barton, P.J., 1998, Three-dimensional seismic refraction tomography: A comparison of two methods applied to data from the Faeroe Basin. J. Geophys. Res. 103, 7187-7210.

Zhang, Z., Bai, Z.M., Wang, C.Y., Teng, J.W., Lü, Q.T., Li, J.L., Liu, Y.F., Liu, Z.K., 2005a. The crustal structure under Sanjiang and its dynamic implications revealed by seismic reflection/refraction profile between Zhefang and Binchuan, Yunnan. Science in China (Series D) 48(9), 329-1336.

Zhang Z., Bai, Z.M., Wang, C.Y., Teng, J.W., Lü, Q.T., Li, J.L., Sun, S.X., Wang, X.Z., 2005b. Crustal structure of Gondwana and Yangtze typed blocks: An example by wide-angle seismic profile from Menglian to Malong in Western Yunnan. Science in China (Series D) 48(11), 1828-1836.

Zhang, Z., Klemperer, S., 2005. West-east variation in crustal thickness in northern Lhasa block, central Tibet, from deep seismic sounding data. J. Geophys. Res. 110 (B9), B09403, doi: 10.1029/2004JB003139.

Zhang, Z., Wang, Y., 2007. Crustal structure and contact relationship revealed from deep seismic sounding data in South China. Physics of the Earth and Planetary Interiors 165, 114-126.

Zhang, Z., Zhang, X., Badal, J., 2008. Composition of the crust beneath Southeastern China derived from an integrated geophysical dataset. J. Geophys. Res. 113, B04417, doi: 10.1029/2006JB004503. 